\title{
POTENTIAL OF USING BIG DATA FOR DISASTER RESILIENCE: THE CASE OF SRI LANKA
}

\author{
A.P. Rathnasinghe ${ }^{1}$ and U. Kulatunga ${ }^{2}$
}

\begin{abstract}
The epoch of big data is evolving new possibilities for Disaster Management (DM). The concept of Big Data has been constantly scrutinised in terms of data creation, storage, retrieval, and analysis where professionals have identified its significance upon the volume, velocity and variety. Big Data provides the opportunity to gather more information in less time. Hence, analysis of Big Data can substantially enhance various disaster resilience activities such as issuing early warnings for evacuations; help emergency response personnel to identify areas that need urgent attention; coordination of disaster management activities; and to identify the most effective response methods for various situations. Therefore, Big Data is identified as a great catalyst for disaster response and, for better understanding of the damage situation and decision-making. Moreover, Big Data has the potential to improve disaster resilience by connecting people, processes, data and technology. However, it is essential to understand the type of Big Data that needs to be generated, to develop the data analysis as in necessary to help with real time responses, decision making and tracking of disaster victim. In order to accomplish the aim, a qualitative research approach was followed. This topical study marked the importance of big data in predicting human behavioral patterns during a disaster. Accordingly, the effective management of human and physical resources in habitual disaster territories was appraised through existing case studies in developed countries. Further, the research has successfully identified the challenges in employing Big Data upon its legal and technological barriers.
\end{abstract}

Keywords: Big Data (BD); Disaster Management (DM); Disaster Resilience.

\section{INTRODUCTION}

Ample natural and human induced disasters strike across the world frequently while mislaying thousands of lives and several more from their habitats and destroying vast amounts of properties (Altay and Green 2006; Galindo and Batta 2013). According to the World Disaster Report of 2015, "more than eight hundred thousand people are killed, and about two billion people were affected by six thousand natural and technological disasters around the world during the last decade" (Hamza, 2015, p.05). Therefore, the effective management of disasters can result in saving an uncountable number of human lives. Accordingly, the concept of DM is comprised of three segments: vigilance, reaction, and retrieval (National Academies Press, 2006). Thus, the assembling, archiving and analysis of disaster related data in a proficient manner is vital for an effective DM. Upon that view,

\footnotetext{
${ }^{1}$ Department of Building Economics, University of Moratuwa, Sri Lanka, akilapr1993@gmail.com

${ }^{2}$ Department of Building Economics, University of Moratuwa, Sri Lanka, ukulatunga@uom.lk
} 
the incorporation of $\mathrm{BD}$ can be identified as a major influence throughout all the stages of DM (Arslan et al., 2017).

This paper comprehends the preliminary findings of the literature synthesis on how Big data has been incorporated into Disaster Resilience (DR) of Sri Lanka in relation with DR mechanisms introduced by the countries like Japan, Philippines and Indonesia. The main reason to incorporate the DR mechanisms from the aforementioned countries is the resemblance of disasters faced by those likeminded cultures to Sri Lanka (Kolb, 2013). Moreover, the legal issues related to Big data is a controversial fact among most DM forums. Consequently, this paper acknowledges the issues related to the end user's privacy and intellectual property rights in Big data application.

\section{BACKGROUND}

Before 2004, Sri Lanka had limited emergency warning mechanisms for natural disasters. However, following the Boxing day Tsunami, the number of data sets used to gather information on disasters has improved. These include satellite data; gauge data from rain, rivers, and reservoirs; information from the South Asian Disaster Knowledge Network, the Meteorology Department, the National Building Research Organisation; daily situation reports and improved hazard maps (Disaster Management Centre, 2013). Further, the 2004 Tsunami resulted in improving the mechanisms to issue early warnings. Currently, the use of SMS to communicate warnings on disasters is common in Sri Lanka. Mainly, the Disaster Management Centre (DMC) in Sri Lanka carries out such communications during disaster situations.

When a forthcoming disaster is being noted, DMC can declare any warnings through the communication mode of SMS without even consulting the service providers. Furthermore, the DMC also uses armed forces, the police and social aid networks like the Sri Lanka Red Cross Society to send out warnings in forms of sirens and loudspeakers (UNESCAP, 2009). In addition to the DMC, private television and radio organisations also use SMS in order to inform the public on disasters. Further, quick and constant updates on forthcoming disasters are also provided through television and radio as "Breaking News". Besides that, emergency warnings and updates on disasters are distributed via social media such as Facebook and Twitter. However, usage of social media is limited to the people living in urban areas and to the working community of Sri Lanka. Those who are in the rural areas and who work in agriculture rarely use social media. Further, government organisations such as the Department of Meteorology provide early warnings through their websites.

\subsection{DATA MANNING AND RESPONDING UPON DISASTERS: EXISTING GAPS}

The success of the early warnings issued through SMS, television and radio was demonstrated during April 2012 when over a million of people in the coastal area were evacuated following a Tsunami warning (Perera, 2012). Despite such successful evacuations and, millions in investments, there are gaps in DM of Sri Lanka in terms of collating the information gathered through various data sets and reaching the grass-root communities who live in rural areas. Further, inadequate national level policy to address data sharing for disaster management on emergency warnings, and the absence of institutionalised data sharing mechanisms among the Government and private organisations have been identified as sensible concerns to achieve effective DM (Disaster Management Centre, 2013). Therefore, the Disaster Management Centre has identified 
the need of integrating all disaster risk management data sharing producers and users into a single platform, promoting online data sharing among national to local and, regional to global level, and setting up an information management hub as the pathway to a future with effective disaster responses (Disaster Management Centre, 2013).

In Sri Lanka, due to the cultural and attitudinal reasons, most of the communities rely on Government based media. Therefore, the lack of trust to act upon SMS, especially if they are issued by private organisations is also evident. This mainly occurred when the severity of the disaster is not as significant as what has been mentioned in the SMS. Similar findings have been noted by the studies carried out in Bangladesh by Kulatunga et al. (2013).

Furthermore, the intervention of Sri Lankan service providers for a successful evacuation during disasters, and extraction of big data on human behavioural patterns during disasters to identify the evacuation pathways and communities with high risk are still in a primary stage. In contrast, countries like Japan use Big Data from service providers for instances such as to plan future responses of residents who are living in an area that has previously suffered from a disaster; records of important population subsets such as areas with elderly communities with infants and youth; to create new best-case scenarios in evacuation procedures for communities and government (Kolb, 2013).

\section{RESEARCH METHOD}

This paper intends to answer the research problem of "how the Big Data concepts and applications can be incorporated into the disaster resilience in Sri Lanka, and to identify the barriers to connect communities during disasters" through a qualitative research method. Thus, the qualitative research method is appraised as its ability to achieve an indepth analysis on incipient and new concepts which are also consisted with a trivial literature supporting. Accordingly, this research is mainly focussed upon an in-depth investigation on literature sources about the incorporation of DM and Big data sources such as; DM protocols published by the Disaster Management Centre of Sri Lanka and the guidelines introduced by countries commonly affected by disaster such as; Japan and Indonesia. Moreover, authors of this article conveyed a considerable attention towards the case studies produced on the relevance of social media platforms and state strategies to collect disaster information in use of future disaster contexts. Consequently, the outcomes of the comprehensive literature analysis have been presented in the form of a conceptual model which is totally based on DM and Big data literature.

\section{DISASTER MANAGEMENT}

In compared to other management disciplines, the concept of DM has not yet been clearly defined or developed. Henstra and McBean (2005) elucidated on DM as a concept which embraces a range of principles and observations which are developed to avoid, manage and diminish the effect of a disaster. Furthermore, Park, Park and Kim (2019) defined $\mathrm{DM}$ as 'a process that includes activities before, during and after a hazard event that aim at preventing disasters, reducing their impacts and recovering from their losses'. However, many literature sources were in a common ideology related to the purpose of $\mathrm{DM}$ as to reduce probable fatalities, safeguard the immediate delivery of suitable backing to affected public and to achieve effective and speedy disaster recapture (Oloruntoba, Sridharan, and Davison, 2017). 


\subsection{Phases of Disaster Management}

Many authors identified mitigation, preparedness, response and recovery as the main phases of DM as identified in Table 1. However, these four factors have been identified in different criteria; Fajardo and Oppus (2010) recognised it in terms of a process, Henstra and McBean (2005) viewed them as theoretical essentials, and O'Brien et al. (2010) appraised these factors as a sequence.

Table 1: Key factors of disaster management

\begin{tabular}{|c|c|}
\hline Classification & Content \\
\hline Mitigation & $\begin{array}{l}\text { - Comprises of recording the past risks, review and appraisal for declining } \\
\text { future risks by means of spatial scheduling, mechanical actions, and } \\
\text { public awareness }\end{array}$ \\
\hline Preparedness & $\begin{array}{l}\text { - Involves emergency planning and training, installation and operation of } \\
\text { monitoring and forecasting warning systems }\end{array}$ \\
\hline Response & $\begin{array}{l}\text { - Response measures aim to maintain or re-establish public safety by search } \\
\text { and rescue operations, and measures to provide for the basic humanitarian } \\
\text { needs of the affected population }\end{array}$ \\
\hline Recovery & $\begin{array}{l}\text { - Includes rapid damage assessment as well as rehabilitation and } \\
\text { reconstruction }\end{array}$ \\
\hline
\end{tabular}

Source: Park, Park and Kim (2019)

Although academic experts have expressed different views on the DM phases and their nature, it was their common doctrine that the involvement of the identified phases of DM will be identified according to the nature of the disaster (Park, Park and Kim, 2019). In other words, the degree of importance will not be the same in all four phases during a particular disaster.

\subsection{DisASTER MANAGEMENT IN SRI LANKA}

Sri Lanka has proven its ability to manage and reduce the effects of natural disasters from the times of its Kings. Accordingly, the ancient rulers introduced reservoirs with a bionetwork controlling method which prospered the country's agronomic culture for many spans (Ministry of Disaster Management, 2014). However, with the advancement of population and human activities, the Sri Lankan authorities are facing challenges related to the effective management and risk reduction of disasters.

The absence of vigilance of first-instance exposures to disasters on First-Aid, Cardiopulmonary Resuscitation (CPR) and the essentials of aged and incapacitated can be identified as one of the foremost loopholes in the DM of the Sri Lankan context (Disaster Management Centre, 2013). Additionally, Sri Lanka is identified to track down a worthy coverage in disaster related data on environment, demography, socio-economic factors, hydrology, soils, water, and climate change. However, effective DM in SL has been affected through poor arrangements to access information which is being composed by different organisations (Ministry of Disaster Management, 2014). Accordingly, this is the instance where the role of Big data takes a place in the DM practice of Sri Lanka so as to ensure the predictability of human behaviours related to disaster environments and effective decision making practise over a disaster. 


\section{A REVIEW OF BIG DATA USED IN DISASTER MANAGEMENT}

As the occurrence of disasters exaggerate over the years, an anxiety has been developed among the people on how modern technology and innovations can be used to avoid, mitigate and manage disasters (Tan et al. 2016). Accordingly, this ideology was further acknowledged by Zheng et al. (2013, p. 451) while stating that "the techniques to efficiently discover, collect, organize, search, and disseminate real-time disaster information have become national priorities for efficient crisis management and disaster recovery tasks". It was further ascertained that the evolving technological revolutions comprising of social media, location-based systems, radio frequency identification, and big data analytics (BDA) are considered as influential gears that may support decision making and forecast throughout the DM phases (Akter and Wamba, 2017).

Upon this view, Mehrotra et al. (2013) promoted that the combination of Big data with DM would bring down a whole new generation of disaster response aspects as it has the prospect of mitigating the disaster effects by enabling access to critical immediate information. The role of Big data in respect of disaster management (DM) has been progressing (Akter and Wamba, 2017). However, previous studies have broadly conversed on reliability and application of sensible and up to date disaster information for DM and training circumstances (Velev and Zlateva, 2012). Accordingly, those studies have concluded on the effect of social media platforms in effective DM.

However, while going beyond the traditional aspect of Big data in DM, Wang et al. (2016) conducted a research on emergency communication systems for disasters, where he has drawn special attention towards Big data. According to him, Big data provides all possible data sets to understand the human behavioural patterns throughout the phases of DM while achieving the optimization of available resources during a disaster. Furthermore, Hristidis et al. (2010) conducted another study directed towards the effective utilization and improvement of data management to mitigate the severe disaster effects. His study highlighted the assortment, management, and presentation of real-time disaster related data throughout the DM process. Pu and Kitsuregawa (2013) acknowledged that Big data related to DM can be primarily obtained through dedicated sensor networks such as seismograph networks, remote sensing sensors

\subsection{Big Data in Disaster Preparation}

$\mathrm{Pu}$ and Kitsuregawa (2013) viewed this stage in the DM process as the most challenging due to the difficulty in predicting the possibilities in a multi-hazardous setup. Accordingly, they highlighted the need of highly accurate big data models to predict the uncountable number of variables and uncertainties.

Jongman et al. (2015) identified the Big data's contribution towards early detection of floods and its various parameters such as possible wave height, period, river's volume capacity to discharge the flood. Further to him, following parameters were obtained through the integration of many data sets from different bases where both isolated sensing data and social media platforms were identified to hold a major role in flood forecast and effect inquiry. Moreover, specifically to social media platforms, social media posts, keywords and hashtags empower relevant authorities to visualize and map locations related to disasters, which have played a vital role in actual flood disaster situations at Pakistan and Philippines (Velev and Zlateva, 2012). 


\subsection{Big DATA IN DiSASTER RESPONSE}

During the DM phase of response, the top priority of relevant authorities should be to ensure the public safety through immediate evacuation and rescue operations. Accordingly, Pu and Kitsuregawa (2013) identified three aspects where Big data can be incorporated and used to improve disaster response. These three aspects are Big data's promising nature to obtain probable identification of critical disaster zones, real time situation study and to recognise the most proficient response from former disaster setups. With the ever increasing usage of smartphones, various data formats can be originated during the due course of a disaster. Rahman, Di and Zannat (2017) acknowledged on those data sets as influential data streams which enable an effective DM process through visualization and GIS mapping. Accordingly, it was reviewed that such data patterns may help in identifying the number of people in critical zones and their ability to self-evacuate or assist in vacating upon their age, medical records, and service provider details (Rahman, Di and Zannat, 2017).

Moreover, many researchers have expressed their viewpoint regarding advanced GPS systems used in software applications such as Google Maps and Find My IPhone. Accordingly, Jongman et al. (2015) revealed the GPS software's ability to provide general evacuation and safety advices which would be unique to a service user; upon user's immaturity or health conditions or incapacity. In view of that, Heinzelman and Waters (2010) revealed on the Haiti earthquake disaster in 2010, where more than 80,000 text messages were scrutinized by the authorities to detect people who required aid to evacuate. A similar technique was followed during the Nepal earthquake, where earthquake details were broadcasted through phone applications and Twitter (Bossu et al., 2015).

\subsection{Big DATA IN DiSASTER RECOVERY}

As the final phase of the DM process, disaster recovery is included with assessing the damages caused by disaster, forming decisions for future from the lessons learnt from the real-time disaster situation and research further to improve disaster resilience. Accordingly, many researches came up with technological innovations to assess the post disaster damages. For an example, Hong et al., (2015) executed parallel processing of Unmanned Aerial Vehicle (UAV) imagery to detect the damages of buildings caused from the Ya' an earthquake in China as three-dimensional models. Further to Hong et al., intervention of UAV as Big data helped to generate rapid information regarding the post disaster management. Moreover, Rahman, Di and Zannat (2017, p 05) discussed on Big data's role in disaster recovery period as "to enhance disaster management capacity for future events".

\subsection{Challenges LinKed WiTH Big DATA}

The combination of Big data and DM is comparatively innovative to many administrative bodies in the world. Therefore, it is inevitably with rising challenges in incorporating Big data to disaster field where Big data's prospects has been ignored in real-time decisionmaking processes. Accordingly, with the high population and rapid increasing of disasters around the world, it is essential to implement much accurate forecasting and early warning systems which Big data has promised in providing (Rahman, Di and Zannat, 2017). Even though large amount of data sets are being produced during a disaster, not every such data set will not be the accurate one. Therefore, it is essential to implement 
the noise removal from these Big data, which is highly challengeable $(\mathrm{Pu}$ and Kitsuregawa, 2013). The language barrier is one severe challenge upon the Big data's approach towards DM. Because, most of these DM specifications are formed on contextual basis where the appropriate translations are to be done prior to the adoption in any country (Rahman, Di and Zannat, 2017).

Legal barriers upon Big data is a burning topic in the technological world which would also be applicable to the DM field as well. Accordingly, data privacy is a universally accepted right of people where many social data of people are being considered private. Therefore, it is a challenge beneath the DM professionals to decide whether the extraction of social media data, service provider data, data relating to family and health would be an intervention to the private autonomy of a person (Pagollo, 2017). Moreover, resilience of big data sets itself is a practical challenge to be considered where the demand for Big data sets would peculiarly increase during a disaster. Therefore, there should be alternative options to Big data because the accessibility to these data is highly vulnerable where the data itself can be easily damaged by the disaster (Rahman, Di and Zannat, 2017).

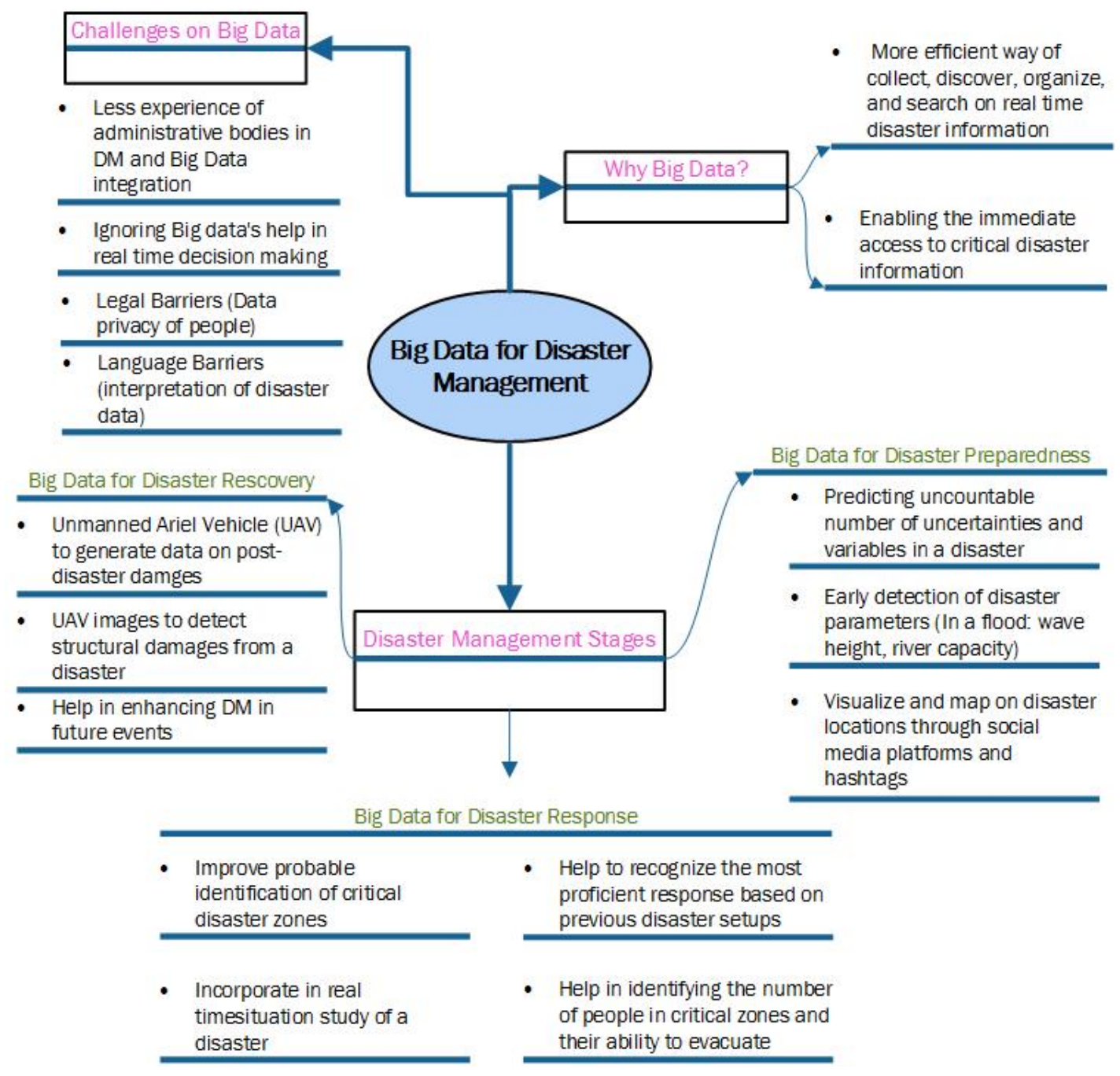

Figure 1: Conceptual model on big data and disaster management combination 


\section{CONCLUSIONS}

It is evident through literature sources that Big data holds a vital role for an effective DM process. Large volume of data from different platforms such as; social media, sensor networks, and other sources have proved their expediency in DM through various realworld case studies. Moreover, the significant features of Big data have promised the administrators and the first responders in disasters to come up with accurate and definite decisions in mitigating the disastrous effects. Further, many sources have proved the existence of Big data in present natural disaster forecasting systems where the probability of a disaster will be measured in comparison to various parameters in a large volume of data set.

Moreover, data sets relating to human behaviours; crowdsourcing, cloud computing, and cyber layouts will help in extracting the required information for the DM. The Big data archive can be supportive for prototype improvement and authentication as to certify more effective DM. However, the integration of Big data and DM is yet a new topic for most of the administrative bodies where they have ignored the importance of Big data in most of their real-time decision making in a disaster. Further, the legality of incorporating human related data for government work is a burning issue in the legal field on the right to privacy. Therefore, most of the policy makers are obeying an indolent path towards such incorporation into the DM field. However, many of the real-world case studies have proven Big data's usefulness and ability to improve the accuracy of disaster prediction which makes its incorporation an inevitable fact.

\section{ACKNOWLEDGEMENTS}

This study is supported by a grant from Senate Research Committee of University of Moratuwa, Sri Lanka (Grant no. SRC/ST/2019/21)

\section{REFERENCES}

Akter, S. and Wamba, S., 2017. Big data and disaster management: a systematic review and agenda for future research. Annals of Operations Research, 86, pp.1587-1592.

Altay, N., and Green, W. G., 2006. OR/MS research in disaster operations management. European Journal of Operational Research, 175, pp.475-493.

Arslan, M., Roxin, A., Cruz, C. and Ginhac, D., 2017. A Review on Applications of Big Data for Disaster Management. In: The $13^{\text {th }}$ International Conference on SIGNAL IMAGE TECHNOLOGY \& INTERNET BASED SYSTEMS [online] Available at: https://hal.archives-ouvertes.fr/hal-01678238/document.

Bossu, R., Laurin, M., Mazet-Roux, G., Roussel, F., and Steed, R., 2015. The Importance of Smartphones as Public Earthquake-Information Tools and Tools for the Rapid Engagement with Eyewitnesses: $A$ Case Study of the 2015 Nepal Earthquake Sequence. Seismological Research Letters, 86, pp.15871592.

Disaster Management Centre (DMC), 2013. Improving Disaster Data to Improve Resilience. Expert Group Meeting with Japan. Colombo: Ministry of Disaster Management.

Fajardo, J.T.B. and Oppus, C.M., 2010. A mobile disaster management system using the android technology. WSEAS Transactions on Communications, 9(6), pp.343-353.

Galindo, G. and Batta, R., 2013. Review of recent developments in OR/MS research in disaster operations management. European Journal of Operational Research, 230, pp.201-211.

Hamza, M., 2015. World Disasters Report 2015: Focus on local actors the key to humanitarian effectiveness. International Federation of Red Cross and Red Crescent Societies.

Henstra, D. and McBean, G., 2005. Canadian disaster management policy: Moving toward a paradigm shift, Canadian Public Policy/Analyse de Politiques, 31(3), pp.303-318. 
Heinzelman, J., and Waters, C., 2010. Crowdsourcing crisis information in disaster-affected Haiti. US Institute of Peace.

Hong, Z., Tong, X., Cao, W., Jiang, S., Chen, P. and Liu, S., 2015. Rapid three-dimensional detection approach for building damage due to earthquakes by the use of parallel processing of unmanned aerial vehicle imagery. Journal of Applied Remote Sensing, 9(1), p.097292.

Hristidis, V., Chen, S. C., Li, T., Luis, S., and Deng, Y., 2010. Survey of data management and analysis in disaster situations. The Journal of Systems and Software, 83, pp.1701-1714.

Jongman, B., Wagemaker, J., Romero, B.R., and de Perez, E.C., 2015. Early flood detection for rapid humanitarian response: harnessing near real-time satellite and Twitter signals. ISPRS International Journal of Geo-Information 4, pp.2246-2266.

Kolb, J., 2013. The Big Data Revolution Kindle Edition. Jason Kolb.

Kulatunga, U., Wedawatta, G., Amaratunga, D., and Shamsuzzoha, M., 2013. Disaster Risk and Community Vulnerability: the Case of Patuakhali, Bangladesh. In: 9th annual international conference of the international institute for infrastructure renewal and reconstruction, 10 July 2013, University of Queensland. Australia.

Mehrotra, S., Qiu, X., Cao, Z., and Tate, A., 2013. Technological challenges in emergency response. IEEE Intelligent Systems, 4, pp.5-8.

Ministry of Disaster Management, 2014. Sri Lanka Comprehensive Disaster Management Programme (SLCDMP). Colombo: Ministry of Disaster Management.

National Academies Press, 2006. Facing hazards and disasters. Washington: Author.

O'Brien, G., O'Keefe, P., Gadema, Z. and Swords, J., 2010. Approaching disaster management through social learning. Disaster Prevention and Management: An International Journal, 19(4), pp.498-508.

Oloruntoba, R., Sridharan, R. and Davison, G., 2018. A proposed framework of key activities and processes in the preparedness and recovery phases of disaster management. Disasters, 42(3), pp.541-570.

Pagallo, U., 2017. The Legal Challenges of Big Data. European Data Protection Law Review, 3(1), pp.3646.

Park, J., Park, S. and Kim, K., 2019. Disaster management and land administration in South Korea: Earthquakes and the real estate market. Land Use Policy, 85, pp.52-62.

Perera, K., 2012. Sri Lanka, the tsunami and the evolution of disaster response - Sri Lanka. [online] ReliefWeb. Available at: https://reliefweb.int/report/sri-lanka/sri-lanka-tsunami-and-evolutiondisaster-response [Accessed 18 Sep. 2019].

Pu, C. and Kitsuregawa, M., 2013. Joint Workshop Report on Big Data and Disaster Management. [online] Georgia Institute of Technology. Available at: https://grait-dm.gatech.edu/wpcontent/uploads/2014/03/BigDataAndDisaster-v34.pdf [Accessed 1 Mar. 2019].

Rahman, S., Di, L. and Zannat, E., 2017. The role of big data in disaster management. In: International Conference on Disaster Risk Mitigation. [online] Available at: https://www.researchgate.net/publication/322265557 [Accessed 1 Apr. 2019].

Tan, X., Di, L., Deng, M., Huang, F., Ye, X., Sha, Z., Sun, Z., Gong, W., Shao, Y. and Huang, C., 2016. Agent-as-a-service-based geospatial service aggregation in the cloud: A case study of flood response. Environmental modelling \& software, 84, pp.210-225

United Nations Economic and Social Commission for Asia and the Pacific (ESCAP), 2009. Tsunami Early Warning Systems in the Indian Ocean and Southeast Asia. Report on Regional Unmet Needs. New York: Tsunami Regional Trust Fund, United Nations.

Velev, D. and Zlateva, P., 2012. Use of social media in natural disaster management. International Proceedings of Economic Development and Research, 39, pp.41-45.

Wang, Y., Zhang, H., He, D., Guo, C., Zhu, W., and Yang, W., 2016. Function design and system architecture of disaster prevention and dispatch system in power system based on big data platform. Dianwang Jishu/Power System Technology, 40(10), pp.3213-3219.

Zheng, L., Shen, C., Tang, L., Zeng, C., Li, T., Luis, S. and Chen, S.C., 2013. Data mining meets the needs of disaster information management. IEEE Transactions on Human-Machine Systems, 43(5), pp.451464. 